\title{
PENGARUH METODE LATIHAN INTERVAL DAN KEMAMPUAN AGILITY TERHADAP PENINGKATAN KETERAMPILAN DRIBBLING PERMAINAN SEPAK BOLA
}

\author{
Mochamad Zakky Mubarok \\ STKIP Nahdlatul Ulama Indramayu \\ mubarokzakky@rocketmail.com
}

\begin{tabular}{l}
\hline Info Artikel \\
\hline Sejarah Artikel: \\
Diterima Oktober 2018 \\
Disetujui November 2018 \\
Dipublikasikan Desember \\
2018
\end{tabular}

\begin{abstract}
Abstrak
Tujuan dari penelitian ini adalahUntuk mengetahui pengaruh antara metode latihan interval intensif dan metode interval ekstensif terhadap peningkatan keterampilan dasar dribbling sepak bola; (Metode yang digunakan dalam penelitian ini adalah eksperimen dengan desain faktorial $2 \times 2$. Populasi 46 orang dan sampel 24 orang di Propelat Soccer School. Hasil penelitian menunjukan bahwa metode interval intensif lebih baik dibandingkan dengan metode interval ekstensif yang dijelaskan pada hipotesis I $(\mathrm{F}=5,554$. P-value $=0,029<0,050)$, Tidak terdapat interaksi pada metode latihan interval dengan kemampuan agility terhadap peningkatan keterampilan dirbbling sepak bola untuk hipotesis II $(\mathrm{F}=0,906$. P-value $=$ $0,353>0,050)$. Kesimpulan hasil penelitian ini adalah: (1) Metode latihan interval intensif memiliki pengaruh yang lebih baik dibandingkan dengan metode interval ekstensif terhadap peningkatan keterampilan dasar dribbling sepak bola; (2) Tidak terdapat interaksi pada metode latihan interval dengan kemampuan agility terhadap peningkatan keterampilan dirbbling sepak bola; (3) Pengaruh metode latihan interval intensif lebih baik dibandingkan dengan metode interval ekstensif pada kelompok kemampuan agility tinggi terhadap peningkatan keterampilan dasar dribbling sepak bola; (4) Pengaruh metode latihan interval ekstensif lebih baik dibandingkan dengan metode interval intensif pada kemampuan agility rendah terhadap peningkatan keterampilan dasar dribbling sepak bola.
\end{abstract}

Keyword:

Abstrack

The purpose of this study is to determine the effect of the intensive interval training method and the extensive interval method on improving the basic skills of football dribbling; (The method used in this study was an experiment with a $2 \times 2$ factorial design. The population was 46 people and a sample of 24 people was at the Proletariat Soccer School. The results showed that the intensive interval method was better than the extensive interval method described in hypothesis I $(F=5.554$. $P$-value $=0.029<0.050)$, There is no interaction with the interval training method with the ability of agility to improve football dirbling skills for hypothesis II $(F=0.906$. $P$-value $=$ $0.353>0.050)$.Conclusions of the results of this study are: (1) 
The intensive interval training method has a better effect than the extensive interval method on improving the basic skills of soccer dribbling, (2) There is no interaction with the interval training method with the ability of agility to improve soccer dirbbling skills, (3) The effect of the method Intensive interval training is better than the extensive pad interval method a group of high agility abilities towards improving basic football dribbling skills; (4) The effect of the extensive interval training method is better than the intensive interval method on the ability of low agility to improve the basic skills of football dribbling.

(C) 2018 Universitas Suryakancana

\begin{tabular}{lr}
\hline Alamat korespondensi: & e-ISSN : 2721-7175 (online) \\
E-mail: & p-ISSN : 2089-2341 (cetak) \\
Adirahadian@unsur.ac.id &
\end{tabular}

\section{PENDAHULUAN}

Untuk dapat bermain sepak bola, pemain harus mengusai teknikteknik dasar permainan sepak bola yang meliputi; menendang bola (kicking), menghentikan bola (stoping), menggiring bola (dribbling), menyundul bola (heading), merampas (tackling), lemparan ke dalam (throwin), dan menjaga gawang (goal keeping). Masing-masing teknik dasar tersebut mempunyai peran dan kedudukan yang sama pentingnya dalam rangkaian suatu pola serangan maupun pertahanan. Salah satu teknik dasar yang memiliki peranan penting dalam permainan sepak bola adalah kemampuan menggiring bola. Teknik menggiring bola adalah suatu upaya mendorong bola secara terputus-putus dan posisi bola tidak jauh dari kaki. Gerakan saat menggiring bola senantiasa berubah-ubah umumnya dapat dilakukan dengan lambat atau mungkin sangat cepat tergantung dari tujuan atau kondisi yang terjadi saat pemain menggiring bola. Mengenai pengertian menggiring bola Sucipto dkk. (2000, hlm. 28) menjelaskan bahwa "Pada dasarnya menggiring bola adalah menendang bola secara terputus-putus atau pelan-pelan, oleh karena itu kaki yang digunakan dribbling sama dengan kaki yang dipergunakan untuk menendang bola. Dan menggiring bola ini ditujukan untuk mendekati arah sasaran, melewati lawan dan mengatur tempo permainan."

Komponen kondisi fisik yang dibutuhkan dalam permainan sepak bola adalah daya tahan otot, power dan kelincahan. Mengenai hal ini, Harsono (1988, hlm. 204) menjelaskan bahwa: "Komponen fisik yang diperlukan dalam cabang olahraga sepak bola antara lain; kekutan otot, daya tahan otot, kelentukan, kelincahan dan power". Komponen kondisi fisik yang mendukung menggiring bola di antaranya fleksibilitas dan kelincahan. Dalam penelitian ini akan dibahas mengenai komponen kondisi fisik kelincahan. Berkenaan dengan pembinaan kondisi fisik bagi atlet sepak bola, khususnya komponen kelincahan, maka latihan-latihan yang diberikan harus dapat meningkatkan kemampuan kelincahan itu sendiri. Wilmore yang dikutip Harsono (1988, hlm. 171) menjelaskan bahwa: “....the 
11| Mochamad Zakky Mubarok

Pengaruh Metode Latihan Interval Dan Kemampuan Agility Terhadap Peningkatan

Keterampilan Dribbling Permainan Sepak Bola

ability to change direction rapidly while maintaining total body balance and awareness of body position". Maksudnya bahwa kelincahan adalah kemampuan untuk mengubah arah dan posisi tubuh dengan cepat dan tepat pada waktu sedang bergerak, tanpa kehilangan kesadaran akan posisi tubuhnya. Kemudian Nurhasan (1999, hlm. 160) menjelaskan bahwa: "Kelincahan menggambarkan kemampuan bergerak kesegala arah."

Pada saat melakukan dribbling, kelincahan berperan dapat memberikan dukungan ketika pemain harus mengubah arah atau posisi tubuh dengan cepat dan tepat pada waktu sedang bergerak tanpa kehilangan keseimbangan. Dengan kelincahan seorang pemain memungkinkan untuk melewati sergapan lawan, karena ketika satu lawan satu ruang gerak pemain untuk melewati lawan dengan ruang geraknya sangat terbatas, dalam hal ini adanya penjagaan yang ketat (presure) dari lawan. Kelincahan menggiring bola dalam permainan sepak bola sangat penting bagi pergerakan mengubah arah dengan cepat, baik dalam pertahanan maupun penyerangan. Hal tersebut perlu didukung oleh keterampilan, kecepatan, keseimbangan dan fleksibilitas pemain itu sendiri, baik pada saat menggiring bola maupun saat melakukan pergerakan tanpa bola untuk menempatkan diri pada posisi yang strategis. Mengenai pentingnya kelincahan dalam menggiring bola Sucipto dkk (2000, hlm. 11), dijelasakan bahwa: "Agilitas itu sangat penting dalam bermain sepak bola seperti untuk menjaga, atau melepaskan jagaaan lawan, dribbling melewati lawan dan masih banyak lagi manufer-manufer yang membutuhkan agilitas dalam permainan sepak bola."

Dengan menggunakan metode latihan interval yang merupakan suatu sistem latihan yang diselingi oleh interval-interval yang berupa masa istirahat seperti yang diungkapkan oleh Harsono (1988, hlm. 156) mengemukakan pengertian "Interval Training adalah suatu sistem latihan yang diselingi oleh interval-interval yang berupa masa-masa istirahat". Pelatihan interval merupakan metode latihan yang sangat ketat dan merupakan salah satu metode yang sangat bagus untuk meningkatkan kemampuan aerobik dan anaerobik menjadi lebih baik. Hal ini sejalan dengan pencetus lahirnya metode latihan interval adalah Zatopek (dalam Sidik, 2011, hlm. 1) bahwa " Ciri dari metode latihan interval adalah konsistensi dalam norma pembebanan, jarak yang ditempuh konsisten, usaha (intensitas) yang dilakukn konsisten, dan yang paling penting adalah masa istirahat yang dilakukan antar pengulangan berlangsung secara konsisten. Cara-cara ini yang dilakukan oleh zapotek ketika persiapan untuk menghadapi Olimpiade Helsinki sehingga ia merebut 3 (tiga) medali emas dalam satu event (Olympic Games) melalui program "Zatopek's Amazing 400 m x 100 reps."

Pada perkembangannya latihan interval menurut Sidik (2006, hlm. 40), metode latihan interval dibagi menjadi metode latihan interval yang ekstensif dan metode latihan interval yang intensif. Menurut Sidik (2006, hlm. 41) Metode interval yang ekstensif adalah sebuah metode latihan yang dilakukan dengan intensitas rendah - sedang dengan denyut nadi dibawah 170x/menit, repetisi banyak, intervalnya singkat dan set/seri yang banyak. Sedangkan metode latihan interval yang intensif adalah sebuah metode latihan yang dilakukan dengan intensitas latihan sedang - tinggi dengan denyut nadi lebih dari 180190x/menit, repetisi sedikit, interval tidak banyak maksimal 3 set. 
12| Mochamad Zakky Mubarok

Pengaruh Metode Latihan Interval Dan Kemampuan Agility Terhadap Peningkatan

Keterampilan Dribbling Permainan Sepak Bola

Apabila dilihat dari
karakteristik pelaksanaanya
kemampuan gerak maksimal agility
merupakan indikator yang sangat
penting dalam menunjang peningkatan
kemampuan menggiring bola
(dribbling) pada pemainan sepakbola. Sejalan dengan penelitian Jovanovic (2011) menjelaskan Program latihan SAQ (speed, agilty and quickness) merupakan cara yang efektif untuk meningkatkan beberapa keterampilan pemain sepak bola di usia muda selama mengikuti periodesasi latihan. Tanpa sebuah perencanaan yang tepat dari latihan SAQ, pemain sepak bola kemungkinan besar akan mengalami penurunan keterampilan.

Mengenai pentingnya pengaruh latihan interval terhadap kemampuan agility sejalan dengan hasil penelitian Dupont dkk. (2004) pengaruh pelatihan interval tinggi pada pemain sepak bola menunjukan hasil bahwa metode interval dengan intensitas tinggi memberikan hasil yang signifikan terhadap peningkatan kemampuan anaerobik dibandingakan dengan pemain yang diberi metode pelatihan seperti biasa.

Dengan menyadari bahwa kemampuan fisik memainkan peranan yang sangat penting maka diperlukan suatu metode latihan untuk mendukung dalam meningkatkan keterampilan. Menurut Giriwijoyo (2010) bahwa Kemampuan fisik harus ditingkatkan agar menjadi tidak mudah lelah, karena merupakan landasan bagi kemampuan teknik.

Oleh karena itu, dalam penelitian ini akan difokuskan pada bentuk-bentuk latihan dengan menggunakan metode interval dan kemampuan agility dalam meningkatkan kemampuan menggiring bola (dribbling) pada permainan sepak bola. Sejalan dengan penelitian Milanovic (2013) bahwa Latihan SAQ (speed, agilty and quickness) merupakan cara yang efektif untuk meningkatkan keterampilan dengan dan tanpa bola untuk pemain sepak bola di usia muda serta dapat dimasukkan dalam program latihan kondisi fisik.

Hal ini yang melatar belakangi penulis untuk melakukan penelitian tentang Pengaruh Metode Latihan Interval Dan Kemampuan Agility Terhadap Peningkatan Keterampilan Dribbling Permainan Sepak Bola. METODE

Metode yang digunakan dalam penelitian ini adalah dengan menggunakan metode eksperimen, pada desain penelitian faktorial. Adapun rancangan penelitian dapat dilihat pada gambar dibawah ini :

\begin{tabular}{|c|c|c|}
$\begin{array}{r}\text { Metode } \\
\text { Latihan }\end{array}$ & $\begin{array}{c}\text { Interval } \\
\text { Intensif } \\
\mathrm{A}_{1}\end{array}$ & $\begin{array}{c}\text { Interval } \\
\text { Ekstensif } \\
\mathrm{A}_{2}\end{array}$ \\
\hline Tingity & $\mathrm{A}_{1} \mathrm{~B}_{1}$ & $\mathrm{~A}_{2} \mathrm{~B}_{1}$ \\
\hline Rendah $\mathrm{B}_{2}$ & $\mathrm{~A}_{1} \mathrm{~B}_{2}$ & $\mathrm{~A}_{2} \mathrm{~B}_{2}$ \\
\hline
\end{tabular}

Gambar Desain Penelitian Faktorial 2 $\mathrm{x} 2$

Keterangan:

$\mathrm{A}_{1}$

: Metode latihan interval intensif

$\mathrm{A}_{2}$

: Metode latihan interval ekstensif

$\mathrm{B}_{1} \quad$ : Tingkat agility tinggi

$\mathrm{B}_{2} \quad$ : Tingkat agility rendah

$\mu \mathrm{A}_{1} \mathrm{~B}_{1} \quad$ : Kelompok siswa yang dilatih menggunakan metode latihan interval intensif dan memiliki agility tinggi

$\mu \mathrm{A}_{1} \mathrm{~B}_{2} \quad$ :Kelompok siswa yang dilatih menggunakan metode latihan interval intensif dan memiliki agility rendah

$\mu \mathrm{A}_{2} \mathrm{~B}_{1} \quad$ :Kelompok siswa yang dilatih menggunakan metode latihan interval ekstensif dan memiliki agility tinggi 
13| Mochamad Zakky Mubarok

Pengaruh Metode Latihan Interval Dan Kemampuan Agility Terhadap Peningkatan

Keterampilan Dribbling Permainan Sepak Bola

$\mu \mathrm{A}_{2} \mathrm{~B}_{2} \quad$ :Kelompok siswa yang dilatih menggunakan metode latihan interval ekstensif dan memiliki agility rendah.

Populasi dalam penelitian ini adalah siswa Propelat Soccer School kelas suratin yang berusia 17 tahun sejumlah 46 siswa. Sampel dalam penelitian ini adalah 24 atlet anggota Propelat Soccer School Bandung, yang dipilih dari tes kemampuan agility yang kemudian hasilnya disusun mulai dari skor tingkat kemampuan agility tinggi sampai dengan atlet yang memiliki tingkat kemampuan agility rendah dengan persentasi $27 \%$ batas atas yang mewakili nilai tinggi dan $27 \%$ batas bawah untuk mewakili batas bawah (Frank M. Veducci 1980, hlm. 176). Jadi jumlah sampelnya masing-masing 12 atlet untuk kelompok kemampuan agility tinggi dan 12 orang untuk kelompok kemampuan agilty rendah. Selanjutnya merujuk Fraenkel dan Welen (1993, hlm. 225) yang menjelaskan tentang pengambilan sampel dalam metode eksperimen desain factorial, dalam pengambilan sampel peneliti menerapkan random assignment. Setelah semua sampel mengikuti tes kemampuan agility, maka peneliti merubah seluruh jumlah sampel menjadi empat kelompok sebagai berikut:
A1

Kelompok Atlet Agility Tinggi

Dengan

Menggunakan

Interval Intensif
$1,4,5,8,9,12$,
B1

Kelompok Atlet Agility Tinggi Dengan Menggunakan Interval Ekstensif

\begin{tabular}{c}
\hline Agility Rendah \\
Dengan \\
Menggunakan \\
Interval Intensif \\
\hline $13,16,17,20,21,24$ \\
\hline
\end{tabular}

Instrumen merupakan alat atau tes yang digunakan untuk mengumpulkan data. Berikut instrumen yang digunakan dalam penelitian ini:

\section{Tes Kemampuan Agiilty.}

Tes kemampuan agility terdiri dari 4 bentuk tes yang bersumber dari Brian Mackenzie (2005), berikut bentuk dan tata cara tes tersebut:

a. Hexagonal Obstacle test

b. Zig-zag Test

c. Illinois Agility Run Test

d. 'T' Drill Test

\section{Tes Keterampilan Dasar Dribbling Sepak Bola.}

Tes keterampilan dribbling bertujuan untuk mengukur, keterampilan, kelincahan, dan kecepatan kaki dalam menggiring bola. Tes keterampilan dribbling ini bersumber dari mor-christian general soccer ability skill test battery.

\section{HASIL}

Pada bagian ini disajikan nilai rata-rata, simpangan baku (standar deviasi), dan simpangan baku gabungan (varian) metode latihan interval intensif dan metode latihan interval ekstensif terkait dengan kelompok yang memiliki agility tinggi dan agility rendah seperti tertuang pada tabel berikut ini:

Tabel Deskriftif data penelitian gain skor
A2

B2

Kelompok Atlet

Kelompok Atlet 
14| Mochamad Zakky Mubarok

Pengaruh Metode Latihan Interval Dan Kemampuan Agility Terhadap Peningkatan

Keterampilan Dribbling Permainan Sepak Bola

\begin{tabular}{|c|c|c|c|c|}
\hline Pendekatan & Agility & Mean & $\begin{array}{c}\text { Std. } \\
\text { Deviation }\end{array}$ & $\mathrm{N}$ \\
\hline Metode & Rendah & 54.83 & 8.18332 & 6 \\
\cline { 2 - 5 } $\begin{array}{c}\text { Latihan } \\
\text { Intensif }\end{array}$ & Tinggi & 53.5 & 11.58879 & 6 \\
\cline { 2 - 5 } & Total & 54.17 & 9.59008 & 12 \\
\hline Metode & Rendah & 48.33 & 5.27889 & 6 \\
\cline { 2 - 5 } $\begin{array}{c}\text { Latihan } \\
\text { Ekstensif }\end{array}$ & Tinggi & 42.67 & 9.77070 & 6 \\
\cline { 2 - 5 } & Total & 45.5 & 8.05097 & 12 \\
\hline \multirow{2}{*}{ Total } & Rendah & 51.58 & 7.39113 & 12 \\
\cline { 2 - 5 } & Tinggi & 48.08 & 11.68105 & 12 \\
\cline { 2 - 5 } & Total & 49.83 & 9.72521 & 24 \\
\hline
\end{tabular}

\begin{tabular}{|c|r|r|r|r|r|r|}
\hline & \multicolumn{1}{|c|}{$\begin{array}{c}\text { Square } \\
\text { S }\end{array}$} & & & & & \\
\hline Metode & 450.667 & 1 & 450.667 & 5.554 & .029 & Signi \\
\hline Agility & 73.500 & 1 & 73.500 & .906 & .353 & \\
\hline Metode*Agility & 28.167 & 1 & 28.167 & .347 & .562 & \\
\hline Error & 1623.000 & 2 & 81.150 & & & \\
& 61776.000 & 2 & & & & \\
\hline Total & 6 & & & & \\
\hline
\end{tabular}

Berdasarkan hasil perhitungan uji ANOVA dua jalur di atas dijelaskan sebagai berikut :

\section{Pengujian Persyaratan Analisa Uji Normalitas}

Pengujian Normalitas dengan menggunakan SPSS 18. Hasil pengujian Normalitas dapat dilihat pada tabel berikut ini:

Tabel Perhitungan Uji Normalitas

\begin{tabular}{|c|c|}
\hline No & Kelompok \\
\hline 1 & Interval Intensif Agility Tinggi \\
\hline 2 & Interval Intensif Agility Rendah \\
\hline 3 & Interval Ekstensif Agility Tinggi \\
\hline 4 & Interval Ekstensif Agility Rendah \\
\hline
\end{tabular}

\section{Uji Homogenitas}

Pengujian Homogenitas dengan menggunakan SPSS 18. Hasil pengujian homogenitas dapat dilihat pada tabel berikut ini :

Tabel Perhitungan Uji Homogenitas

\begin{tabular}{|c|c|c|}
\hline No & Kelompok & P - vahbe litian Kiondisierdan tKeterangan \\
\hline 1 & Varians Gabungan & 0,58 Reteramnil $\mathrm{Pn}>\partial_{k}$ \\
\hline
\end{tabular}

Berdasarkan tabel perhitungan statistic di atas dikarenakan $p$-value $=$ $0,580>0,050$ maka data siambil dari sampel yang homogen.

\section{Pengujian Hipotesis}

Pengujian analisis of varians (Anova) setalah dilakukan uji persyaratan, berikut hasil perhitungan anova dua jalur dapat dilihat pada tabel berikut ini :

Tabel Perhitungan Anova Dua Jalur

\begin{tabular}{|c|c|c|c|c|}
\hline \multirow{3}{*}{ Source } & $\begin{array}{c}\text { Type } \\
\text { III } \\
\text { Sum of }\end{array}$ & $\begin{array}{c}\text { D } \\
\text { f }\end{array}$ & $\begin{array}{c}\text { Mean } \\
\text { Squar }\end{array}$ & F \\
& Sum \\
\hline
\end{tabular}

yang memperoleh latihan metode interval intensif dan latihan metode latihan interval ekstensif.

Hal ini dibuktikan dengan terdapat perbedaan keterampilan dribbling antara siswa yang memperoleh metode interval intensif dan ekstensif.

Tabel Nilai Rata-rata Metode Latihan dan Kemampuan Dribbling Gain Skor

\begin{tabular}{|c|c|c|c|}
\hline $\begin{array}{l}\text { Interval } \\
\text { Agiliteta }\end{array}$ & Intensif & Ekstensif & Total \\
\hline $\begin{array}{c}\text { ngan } \\
\text { Tinggi }\end{array}$ & 53,5 & 142,67 & 96,17 \\
\hline
\end{tabular}


15| Mochamad Zakky Mubarok

Pengaruh Metode Latihan Interval Dan Kemampuan Agility Terhadap Peningkatan Keterampilan Dribbling Permainan Sepak Bola

\begin{tabular}{|c|c|c|c|}
\hline & & & \\
\hline \multirow{2}{*}{ Rendah } & 54,83 & 48,33 & 103,16 \\
\hline & 108,33 & 91 & \\
\hline
\end{tabular}

Terdapat interaksi pada metode latihan interval dengan kemampuan agility terhadap peningkatan keterampilan dirbbling sepakbola.

Berdasarkan perolehan perhitungan ANOVA interaksi dua faktor di peroleh nilai signifikansi sebesar 0,562>0,05 untuk gain skor. Maka diketahui bahwa dalam penelitian ini tidak terdapat interaksi yang signifikan antara metode latihan dan kemampuan agility terhadap keterampilan dribbling.

Selanjutnya untuk mengetahui hipotesis 3 yaitu pengaruh metode latihan interval intensif lebih baik dibandingkan dengan metode interval ekstensif pada kelompok kemampuan agility tinggi terhadap peningkatan keterampilan dasar dribbling sepak bola. Dan hipotesis 4 yaitu pengaruh metode latihan interval ekstensif lebih baik dibandingkan dengan metode interval intensif pada kemampuan agility rendah terhadap peningkatan keterampilan dasar dribbling sepak bola. Dikarenakan pada hipotesis yang kedua terjawab bahwa tidak terdapat interaksi pada metode latihan interval dengan kemampuan agility terhadap peningkatan keterampilan dirbbling sepak bola, maka untuk menjawab hipotesis ketiga dan keempat bahwa tidak akan ada interaksi untuk menjawab hipotesis tersebut.

Diskusi Penemuan.

Pengaruh metode latihan interval intensif memiliki pengaruh yang lebih baik dibandingkan dengan metode interval ekstensif terhadap peningkatan keterampilan dasar dribbling sepak bola.
Berdasarkan hasil penelitian penulis, dan didukung oleh beberapa penemuan hasil penelitian sebelumnya dan pemaparan para ahli. Ternyata hasil keterampilan dribbling yang dilatih melalui metode latihan interval intensif lebih baik dibandingkan siswa yang dilatih melalui latihan metode interval ekstensif. Kenyataan dilapangan secara keseluruhan kelompok latihan yang menggunakan metode latihan interval intensif menunjukkan skor rata-rata yang lebih besar dibandingkan dengan kelompok yang menggunakan metode latihan interval ektensif. Dengan kata lain, pelaksanaan program latihan dengan intensitas latihan sedang - tinggi dengan denyut nadi lebih dari 180-190 $\mathrm{x} /$ menit, repetisi sedikit, interval tidak banyak maksimal 3 set dengan pengaturan waktu istirahat di antara repetisi dan di antara set menunjukkan pengaruh yang lebih baik untuk peningkatan kemampuan dribbling dalam permainan sepakbola. Hal demikian merupakan suatu indikasi bahwa metode latihan interval intensif menunjukkan keunggulan dalam meningkatan kemampuan dribbling dibandingkan dengan metode latihan interval ektensif.

Seperti yang diterangkan oleh Taga dan Asai (2011) bahwa dengan pelatihan dribbling intensif (DRI-TI) menunjukan peningkatan terhadap keterampilan dribbling sepakbola, kemudian sejalan dengan hasil penelitian-penelitian Gibala dkk. (2005) dan Tabata dkk. (1996) menunjukkan peningkatan yang besar dalam sistem energi anaerobik dengan intensitas tinggi, interval training memiliki manfaat dan penampilan hasil yang luar biasa.

Maka dari hasil penelitian ini memperkuat penelitian yang diungkap oleh Taga dan Asai (2011) bahwa dengan pelatihan dribbling intensif (DRI-TI) menunjukan peningkatan 
16| Mochamad Zakky Mubarok

Pengaruh Metode Latihan Interval Dan Kemampuan Agility Terhadap Peningkatan

Keterampilan Dribbling Permainan Sepak Bola

terhadap keterampilan dribbling, juga sama halnya dengan hasil penelitian Dupont dkk. (2004) pengaruh pelatihan interval tinggi pada pemain sepak bola, menunjukan hasil bahwa metode interval dengan intensitas tinggi memberikan hasil yang signifikan dibandingakan dengan pemain yang diberi metode pelatihan seperti biasa.

Tidak terdapat interaksi pada metode latihan interval dengan kemampuan agility terhadap peningkatan keterampilan dribbling sepak bola.

Berdasarkan hasil penelitian adanya interaksi antara metode latihan interval dengan kemampuan agility terhadap keterampilan dribbling, menunjukkan bahwa metode interval dan kemampuan agility tidak memberikan hasil yang signifikan terhadap peningkatan keterampilan dribbling sepak bola, ini terjadi disebabkan adanya beberapa ancaman dalam eksperimen yang dipengaruhi oleh situasi pengendalian dari validitas ekstrenal dan validitas internal. Hal tersebut terjadi ketika dalam pelaksanaan penelitian dipengaruhi beberapa faktor dan kegiatan yang mengancam pengendalian. Berdasarkan gambaran tersebut maka berpengaruh terhadap hasil interaksi dari jawaban hipotesis. Di bawah ini beberapa temuan dilapangan diantaranya :

a. Karena penerapan metode latihan interval intensif dengan penerapan metode latihan interval ekstensif pada kelompok sampel dengan kemampuan agility rendah lebih tinggi peningkatan rata-rata gain skor keterampilan dribbling dibandingkan penerapan metode interval intensif dan ekstensif pada kelompok sample dengan kemampuan agility tinggi. Berikut di bawah ini grafik gain skor peningkatan keterampilan dribbling dari seluruh kelompok sampel, yaitu:

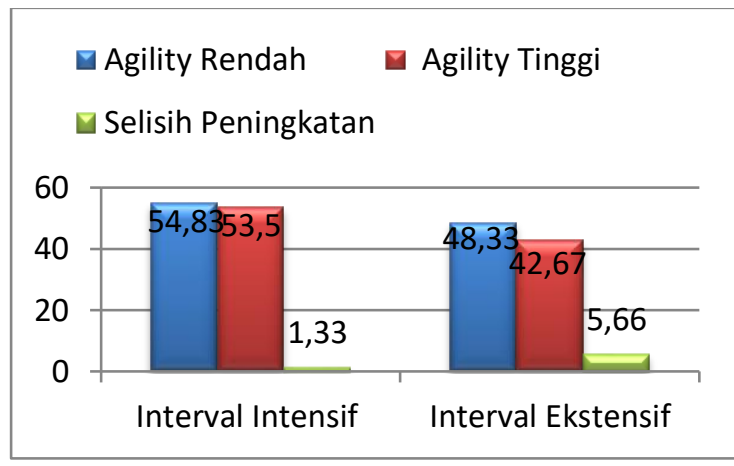

Grafik Gain Skor Peningkatan

Dribbling Seluruh Kelompok Sampel

Dari grafik peningkatan di atas terlihat metode latihan interval intensif dan metode latihan interval ekstensif pada kelompok sampel dengan kemampuan agility rendah lebih tinggi peningkatan rata-rata gain skor keterampilan dribbling, dibandingkan penerapan metode latihan interval intensif dan meode interval ekstensif pada kelompok sampel dengan kemampuan agility tinggi. Hal ini yang membuat temuan dilapangan yang mengakibatkan tidak terjadi interaksi. Hal ini merujuk pada teori BKM (Batas Kemampuan Maksimal) seseorang, yang lebih jelas dikemukakan oleh Giriwijoyo dan Sidik (2012, hlm. 230) bahwa "Batas kemampuan maksimal (BKM) akan menjadi faktor pembatas bagi penampilan atlet dalam menampilkan prestasinya yang maksimal." Maka oleh karena itu kelompok sampel yang memiliki kemampuan agility rendah diduga mengalami BKM, sehingga diperlukan penelitian lebih lanjut atau pelatihan yang lebih sistematis dan lebih lama 
sesuai periodisasi latihan, sehingga dapat memperoleh hasil pelatihan yang lebih signifikan.

b. Selain hal itu tidak terdapat interaksi karena jumlah sampel pada penelitian ini sedikit, hal ini dikarenakan keterbatasan waktu dan sampel penelitian sehingga berdampak pada hasil dan pengolahan data dengan selisih angka terlalu tipis oleh karenanya diperlukan penelitian lebih lanjut dengan jumlah sampel yang lebih banyak.

c. Kendala lain yang dihadapi dalam penelitian ini adalah keterbatasan alat dalam menghitung dan mengetahui denyut nadi pemain saat melakukan proses latihan. Oleh karena itu pengawasan yang harus baik karena dalam metode latihan interval pemain harus selalu menyelesaikan program latihan setiap repetisi/set latihan dengan baik, guna meraih denyut nadi latihan yang diharapkan.

d. Selain itu juga dalam pelaksanaanya disadari bahwa metode latihan interval dengan tujuan peningkatan fisik, pemain harus mempunyai kemampuan agility yang baik guna meraih tujuan yang maksimal. Ada beberapa pemain dalam kelompok sampel penelitian ini yang memang kurang memiliki kemampuan kemampuan agility yang baik, maka pengawasan ekstra dalam proses latihan harus selalu dilakukan.

e. Selain itu, faktor kondisi lapangan juga menjadi sebuah kendala, karena semakin baik kondisi lapangan maka akan semakin mudah bola dikuasai saat melakukan dribbling, sebaliknya apabila lapangan kurang baik maka akan sulit untuk menguasai bola dalam melakukan dribbling.

Berdasarkan gambaran tersebut maka berpengaruh terhadap hasil interaksi dari jawaban hipotesis.

\section{Pengaruh metode latihan interval intensif lebih baik dibandingkan dengan metode latihan interval ekstensif pada kelompok kemampuan agility tinggi terhadap peningkatan keterampilan dasar dribbling sepak bola.}

Berdasarkan hasil penelitian dilapangan secara keseluruhan kelompok siswa yang menggunakan metode latihan interval intensif dengan kemampuan agility tinggi menunjukkan skor rata-rata yang lebih besar dibandingkan dengan kelompok yang menggunakan metode interval ektensif dengan kemampuan agility tinggi. Dengan kata lain, kemampuan agility tinggi yang mengikuti program latihan metode interval intensif dengan intensitas latihan sedang - tinggi dengan denyut nadi lebih dari 180 190x/menit, repetisi sedikit, interval tidak banyak, dengan pengaturan waktu istirahat diantara repetisi dan diantara set menunjukkan pengaruh yang lebih baik terhadap peningkatan kemampuan dribbling dalam permainan sepak bola. Hal demikian merupakan suatu indikasi dengan kemampuan agility tinggi, metode latihan interval intensif menunjukkan keunggulan dibandingkan metode latihan interval ektensif dalam peningkatan kemampuan dribbling.

Pengaruh metode latihan interval ekstensif lebih baik dibandingkan dengan metode latihan interval intensif pada kelompok kemampuan agility rendah terhadap peningkatan keterampilan dasar dribbling sepak bola.

Berdasarkan temuan dilapangan bahwa metode latihan interval ekstensif lebih memberikan hasil yang lebih baik 
18| Mochamad Zakky Mubarok

Pengaruh Metode Latihan Interval Dan Kemampuan Agility Terhadap Peningkatan

Keterampilan Dribbling Permainan Sepak Bola

dibandingkan dengan metode latihan interval intensif pada kelompok siswa dengan kemampuan agility rendah, dilihat dari hasil temuan dilapangan sampel yang mengikuti program latihan dengan metode latihan interval ektensif yang dalam pelaksanaannya dilakukan dengan intensitas rendah sedang, denyut nadi dibawah 170x/menit, repetisi banyak, intervalnya singkat dan set/seri yang banyak menunjukkan pengaruh yang lebih baik untuk peningkatan kemampuan dribbling. Hal ini merupakan suatu indikasi bahwa metode latihan interval ekstensif menunjukkan keunggulan dalam peningkatan kemampuan dribbling dibandingkan dengan metode latihan interval intensif pada kelompok siswa dengan kemampuan agility rendah. Sejalan dengan Shaleh (dalam Adhegora, 2011, hlm. 1) bahwa metode latihan dengan kegiatan yang berupa pengulangan yang berkali-kali supaya asosiasi stimulus dan respons menjadi sangat kuat dan tidak mudah untuk dilupakan.

Dengan demikian siswa dengan kemampuan agility rendah yang menggunakan metode latihan ekstensif mengalami BKM (Batas Kemampuan Maksimal) sehingga menampilkan kemampuan yang maksimal dalam peningkatan keterampilan dribbling. Hal tersebut merujuk pada teori BKM (Batas Kemampuan Maksimal) seseorang, menurut Giriwijoyo dan Sidik (2012, hlm. 230) bahwa "Batas kemampuan maksimal (BKM) akan menjadi faktor pembatas bagi penampilan atlet dalam menampilkan prestasinya yang maksimal."

\section{KESIMPULAN DAN SARAN Kesimpulan}

Hasil penelitian ini menemukan kesimpulan bahwa: (1) Metode latihan interval intensif memiliki pengaruh yang lebih baik dibandingkan dengan metode interval ekstensif terhadap peningkatan keterampilan dasar dribbling sepak bola; (2) Tidak terdapat interaksi pada metode latihan interval dengan kemampuan agility terhadap peningkatan keterampilan dasar dribbling sepak bola; (3) Pengaruh metode latihan interval intensif lebih baik dibandingkan dengan metode interval ekstensif pada kelompok kemampuan agility tinggi terhadap peningkatan keterampilan dasar dribbling sepak bola; (4) Pengaruh metode latihan interval ekstensif lebih baik dibandingkan dengan metode interval intensif pada kemampuan agility rendah terhadap peningkatan keterampilan dasar dribbling sepak bola.

\section{Saran}

Berdasarkan hasil penelitian membuktikan bahwa metode latihan interval intensif lebih baik dibandingkan metode latihan interval ekstensif terhadap peningkatan keterampilan dasar dribbling dalam permainan sepakbola. Bagi para pelatih olahraga disarankan agar menggunakan metode latihan interval intensif untuk meningkatkan keterampilan dribbling pemain sepak bola. Karena dengan penerapan metode latihan intensif memberikan dampak terhadap peningkatan rata-rata keterampilan dribbling pemain sepak bola, maka disarankan agar para pelatih sepak bola merancang program latihan secara spesifik tentang metode latihan interval intensif tidak hanya untuk peningkatan dribbling saja tetapi dalam berbagai aspek pelatihan sepak bola. Dengan menggunakan metode latihan interval intensif yang bervariasi sesuai dengan kebutuhan latihan akan lebih bermakna dan tepat kepada sasaran pelatihan. Untuk penelitian lebih lanjut disarankan agar pengembangan keilmuan dalam metode kepelatihan yang lebih efektif dan efisien maka 
19| Mochamad Zakky Mubarok

Pengaruh Metode Latihan Interval Dan Kemampuan Agility Terhadap Peningkatan

Keterampilan Dribbling Permainan Sepak Bola

dalam penelitian ini dapat dikembangkan melalui kajian lain atau penerapan pada kelompok lain seperti gender, kelompok usia, jenjang olahraga (pada jenjang pembinaan atau jenjang professional).

\section{DAFTAR PUSTAKA}

Adhegora. (2011). Metode Drill Menurut Para Ahli. [Online]. Tersedia:

http://adhegora.blogspot.com/2 012/04/metode-drill-menurutparaahli.html. [Diakses 14 Februari 2014]

Bloomflied, Jonathan. et al. (2007). Effective Speed and Agility Coditioning Methodology for Random Intermitent Dynamic Type Sports. Journal of Strenght and Conditioning Reasearch, 2007, 21 (4), hlm. 1093-1100

[Online].Tersedia:http://www.r esearchgate.net/publication/57 72787_Effetive_speed_and_ag ility_conditioning_methodolog y_for_random_intermittent_dy namic_type_sports/file/d912f5 0f6a5898c873.pdf. [Diakses 23 Februari 2014]

Dupont, Gregory. et al. (2004). The Effect Of In-Season, HighIntensity Interval Training In Soccer Players. Dalam Journal of Strenght and Conditioning Reasearch, 18 (3), 584-589 [Online]. Tersedia: http:// anneclairepannier.free.fr/files /foot/Dupont\%202004\%20$\% 20$-Interval

Training\%20Soccer.pdf

[Diakses 23 Februari 2014]

Fraenkel, Jack. R. et al. (1993). How To Design and Evalute Research In Education. New York: McGraw Hill-Inc.

Gibala, et al. (2005). "Six Sessions Of Sprint Interval Trainning
Increases Muscle Oxidative

Potential and Cycle

Endurance capacity in

Humans". Journal Of Applied

Physiology.98, (1), 19851989.

Giriwijoyo, Santosa dan Zafar, Dikdik. 2012. Ilmu Faal Olahraga (Fisiologi Olahraga). Bandung: Rosda

Harsono. (1988). Coaching dan AspekAspek Psikologis Dalam Coaching. Jakarta : CV. Tambak Kusuma.

Jovanovic, M (2011). "Effects of speed, agility, quickness training method on power performance in elite soccer players". Journal of strenght and conditioning reseacrh. Tersedia http://www.ncbi.nlm.nih.gov/ pubmed/2152207. (diakses 18 Agustus 2014)

Mackenzie, Brian. (2005). 101 Evaluation Test. London: Electric Word plc.

Milanovic. Z (2013), "Effects of a 12 Week SAQ Training Programme on Agility with and without the Ball among Young Soccer Players." Journal Medicine and Science in Sport and Exercise. Tersedia : http://www.ncbi.nlm.nih.gov /pubmed/24149731 (diakses 17 Agustus 2014)

Mor and Christian (1979). General Soccer Ability Skill Test Battery.

Nurhasan. (1999). Tes dan Pengukuran: Jurusan Pendidikan Kepeatihan Olahraga - FPOK UPI Bandung.

Pesurnay, P. Levius \& Sidik, Zafar. (2006). Materi Penataran Pelatihan Fisik Tingkat Propinsi Se-Indonesia. 
20| Mochamad Zakky Mubarok

Pengaruh Metode Latihan Interval Dan Kemampuan Agility Terhadap Peningkatan

Keterampilan Dribbling Permainan Sepak Bola

\section{Jakarta: $\quad$ Komisi \\ PUSDIKTAR KONI Pusat}

Sucipto, dkk. (2000).Sepak Bola. Jakarta: Departemen Pendidikan Nasional.

Sugiyono. (2013). Metode Penelitian Kuantitatif, Kualitatif dan $R \& D$. Bandung: CV. Alfabeta.

Tabata, et al. (1996). "Effect of Moderate-Intensity Endurance and High-Intensity Intermitten Trainning on Anaerobic Capacity and VO2max". Journal Medicine and Science in Sport and Exercise.28, (10), 1327-1330.

Taga, Ken dan Asai, Takeshi. (2011). The Influence of Short-term Intensive Dribbling Training on Ball Skill -Intend for Footballers of an Eighth Grader. Journal. Football
Science, (9), hlm. 35-49 [Online]. Tersedia di: www.shobix.co.jp/jssf/tempfiles /journal/2012/ 038.pdf. [Diakses 7 Maret 2014]

Verducci, Frank. M. (1980). Measurement Concepts In Physical Educstion. San Fransisco: State University

Zafar, Dikdik. (2006). Latihan Kondisi Fisik, Klinik Kepelatihan Pelatih Fisik Sepak Bola Tingkat Nasional. Bandung

Zafar, Dikdik. (2011). Manfaat Pelatihan Harness Dalam Meningkatkan Kemampuan Aerobik dan Anaerobik. [omlina]. Tersedia:http//dizas424starpe rformance.blogspot.com/). [Diakses 7 Maret 2014 